\title{
APPROACHES TO EMBEDDING GLOBAL DIMENSION IN ADULT EDUCATION CURRICULUM BY THE CASE STUDY OF THE HOSPITALITY BUSINESS TOOLKIT
}

\author{
Olga Zvereva \\ Hotel School Hotel Management College, Latvia
}

\begin{abstract}
The purpose - The paper aims to present a conceptual overview of the approaches to embed Global Dimension in Adult Education Curriculum to learn and share global practices with adult educators and promote Education for Sustainable Development and Global Citizenship (ESDGC) for achieving the Sustainable Development Goals' targets including SDG4 Quality Education and overall enhancing education.

The theoretical framework - Global Dimension including the concepts of Sustainable Development and Global Citizenship is initially related to the subject-oriented approach, the principles of Education for Sustainable Development (ESD) as well as ESDGC including SDGs are based on the principles of the competences leading to competencies that point at competency-based and problem-based approaches, but the qualification competences frame to curriculum-based approach. This overview provides a summary of the approaches to embed Global Dimension in adult education curriculum with discussion of the benefits, applicability and synthesis of various approaches as well as practical case framework by the example of the Hospitality Business Toolkit, a course designed by Pearson, the Business and Technology Education Council (BTEC).

The research/ study design - The framework is developed from a review of literature on the principles, approaches and global practices of embedding Global Dimension, ESD, ESDGC in the curriculum, interrelated with the qualification learning outcomes.

The methods or instruments - The grounded theory, an exploratory method, was used for identification and conceptualization of the patterns to structure findings by the process of comparison of different approaches and practices. A case study was designed to demonstrate a practical application of optional embedding Global Dimension in the course design.

The description of the experience - The case illustrates the initially built-in concepts of Global Dimension by Pearson, BTEC by integrated legal, ethical and social, financial, human resource and department coordination aspects with additional optionally embedded sustainability topics in the course design.

The findings - The unity between the content, form and context with a synthesis of approaches to embed Global Dimension, ESD, ESDGC in the curriculum is of utmost importance.
\end{abstract}

Key words: Global Dimension, Education for Sustainable Development and Global Citizenship (ESDGC), embedding, approaches, learning challenges, hospitality. 


\section{Introduction}

The paper provides a theoretical review and practical case study of the approaches to embed Global Dimension in the Pearson BTEC Unit the Hospitality Business Toolkit with analysis of the related aspects linked to ESD, ESDGC, the hospitality business manager competences leading to competencies and entrepreneurship skills.

According to McGough, Hunt,, (2012, p. 8), University of London, the global dimension connects the local, national and global in a way that people are aware of how their actions have implications for others across the globe. The term the global dimension can be used alongside other terms such as global learning, development education and global citizenship education (McGough, Hunt, 2012, p. 8).

Global Education Guidelines Concepts and Methodologies on GE for Educators and Policy Makers by GEGWG, the North-South Centre (NSC) of the Council of Europe (2012, p. 10) mention Global Education as an education perspective which arises from the fact that contemporary people live and interact in an increasingly globalised world.

Europe-wide Global Education Congress (2002, p. 2) defines GE as education that opens people's eyes and minds to the realities of the world, and awakens them to bring about a world of greater justice, equity and human rights for all, where the GEGWG $(2012$, p. 6) enriches the explanation of the definition by the word 'holistic education'.

Global Education by the Maastricht Global Education Declaration (2002, p. 2) is understood to encompass Development Education, Human Rights Education, Education for Sustainability, Education for Peace and Conflict Prevention and Intercultural Education; being the global dimensions of Education for Citizenship. In addition, GEGWG (2012, p. 20) admits that GE enables people to develop the knowledge, skills, values and attitudes needed for securing a just, sustainable world in which everyone has the right to fulfil his/her potential.

Bourn (2012) mentions that the concept of the Global Dimension was constructed in 2000 by development education organisations in partnership with the Labour government as a mechanism for taking forward many of the themes behind development education practice through a series of concepts such as sustainable development, conflict resolution, values and perspectives, interdependence. Qualifications and Curriculum Authority (2008, p. 2) states that 'the GD explores what connects us to the rest of the world. It enables learners to engage with complex global issues and explore the links between their own lives and people, places and issues throughout the world. The GD can relate to both developing and developed countries, including countries in Europe. It helps learners to 
imagine different futures and the role they can play in creating a fair and sustainable world.'

Sustainable Development Goal 4 Quality Education (SDG4) of the 17 SDGs is to ensure inclusive and equitable quality education and promote lifelong learning opportunities for all (United Nations, 2015, "The 2030 Agenda for Sustainable Development"). The target 4.4 is 'By 2030, substantially increase the number of youth and adults who have relevant skills, including technical and vocational skills, for employment, decent jobs and entrepreneurship'. The target 4.7 is 'By 2030, ensure that all learners acquire the knowledge and skills needed to promote sustainable development, including, among others, through ESD and sustainable lifestyles, human rights, gender equality, promotion of a culture of peace and non-violence, global citizenship and appreciation of cultural diversity and of culture's contribution to sustainable development'. The indicator to measure the target 4.7 is 4.7 .1 the extent to which (i) global citizenship education and (ii) ESD, including gender equality and human rights, are mainstreamed at all levels in: (a) national education policies, (b) curricula, (c) teacher education and (d) student assessment (United Nations, 2015, "The 2030 Agenda for Sustainable Development").

Research problem has been figured out that GD including the concepts of Sustainable Development and Global Citizenship is initially related to the subject-oriented approach, the principles of ESD as well as ESDGC including SDGs are based on the principles of the competences leading to competencies that point at competency-based and problem-based approaches, but the qualification competences frame to curriculum-based approach. The identified problem is the absence of clarity and framework for approach application to embed GD in Adult Education Curriculum with relation to Learning Outcomes and Qualifications.

Research background can be found in co-authored published article (2017) 'Key Competencies of Managerial Level Employees for Sustainability in Hospitality Business' and a conducted research and designed intellectual outputs on approaches to embed ESDGC in adult education for EU Erasmus Plus KA2 ESDGC Project. The updated Pearson BTEC Hospitality Management Programme 2018 was introduced and implemented instead of Programme 2010.

The Aim of the Research The paper aims to present a conceptual overview of the approaches to embed Global Dimension in Adult Education Curriculum to learn and share global practices with adult educators and promote ESDGC for achieving the Sustainable Development Goals' (SDGs') targets including SDG4 Quality Education and overall enhancing education.

Research Function and Application This overview provides a summary of the approaches to embed GD in adult education curriculum with 
discussion of the benefits, applicability and synthesis of various approaches as well as practical case framework by the example of the Hospitality Business Toolkit.

Research Objectives are: to establish approach framework for embedding GD in Adult Learning Curriculum; to illustrate an approaches and techniques how to embed GD in Adult Curriculum by case design and analysis; to develop a proposal of methods and topics to embed GD in Adult Learning Curriculum.

Research Object is the approaches to embed GD in Adult Learning Curriculum.

Research Subject is the ways to select and apply approaches to embed GD in Adult Learning Curriculum to achieve Sustainable Development Goals including SDG4 Quality Education and enhance overall education.

\section{Theoretical Framework}

The framework is developed from a review of literature on the principles, approaches and global practices of embedding GD, GE, ESD, ESDGC in the curriculum, interrelated with the qualification learning outcomes.

\section{Relation of Global Education, Global Dimension, ESD and ESDGC}

The theoretical definitions and relation of Global Education, Global Dimension, ESD and ESDGC are reviewed to clarify the relevant approaches.

OGEGWG (2012, p. 10) states it is "crucial for education to give learners the opportunity and competences to reflect and share their own point of view and role within a global, interconnected society, as well as to understand and discuss complex relationships of common social, ecological, political and economic issues, so as to derive new ways of thinking and action. At the same time GEGWG (2012, p. 10) defines GE as approach itself and ascertains that 'GE should not be presented as an approach that we may all accept uncritically, since we already know there are dilemmas, tensions, doubts and different perceptions in an education process when dealing with global issues'.

The Global Education Guidelines Working Group (GEGWG, 2012, p. 17) delineates that ' $\mathrm{GE}$ is a new approach which aims at enabling learners to understand world issues while empowering them with knowledge, skills, values and attitudes desirable for world citizens to face global problems. The global challenges and the theoretical pattern of GE are separated into a system of spatial, objective/issues, temporal, and social dimensions (Lehner, Wurzenberger, 2013, p. 361).

Mannion et al (2011, p. 448) discuss the concept by Davies, Evans, and Reid (2005), 'the Environmental Education (EE), Development Education 
(DE) and Citizenship Education (CE) lineages potentially converging on a nodal point in their respective discourses' illustrated as Education for Global Citizenship. By Mannion et al (2011, p. 448), EE includes Nature Studies, Global Learning, ESD, the route of DE involves Third World Studies, Peace Education, Global Education, ESD, but CE emerge as Civic Studies, Entrepreneurial Education, International Education.

Global Dimension, GE, ESD, ESDGC are interrelated, the approaches to ESD are traceable with the focus on GD. Pedagogical approaches and principles that have been analysed by UE4SD (2014, p. 57) within national ESD strategies in the European countries include whole-of-institution, strategic/systemic, competence/skills-based, and future thinking. ESD principles by UE4SD (2014, p. 57) are critical/creative thinking, action learning, systemic thinking, participation/ partnerships.

GEGWG (2012, p. 20) determines that 'GE is not just concerned with different perspectives on globalised themes and what you teach and learn about them. It is also concerned about how you teach and learn and the contextual conditions in which you teach and learn. In fact there is a necessary unity between the content, form and context in which the learning process takes place.'

'Core values allow educators to clarify the basic principles of the learning process, guiding them in choosing the contents, identifying and using sources of information, designing teaching-learning-evaluating strategies and developing fields of practical intervention for the learner. The ultimate purpose of GE is to develop values, based on knowledge of global issues and relevant skills in order to build attitudes for responsible global citizenship at individual and collective level' (GEGWG, 2012, p. 24). The values include self-esteem, self-confidence, self-respect and respect for others, social responsibility, environmental responsibility, openmindedness, visionary attitudes, proactive and participatory community membership, and solidarity (GEGWG, 2012, p. 24).

According to the Department for International Development (DFID), (2005, p. 7) the global dimension contributes to the development of key skills including communication, cross-cultural communication, working with others, and an awareness of diverse perspectives on issues. It contributes to thinking skills by encouraging pupils to analyse, evaluate, question assumptions; and creatively identify ways to achieve positive change.

Development Education Association (2000, p. 3) has outlined the eight principles of GD. The Department for International Development (2005, p. 20), specify that these concepts provide a conceptual framework for thinking about and building them into the curriculum: global citizenship, conflict resolution, social justice, values and perceptions, sustainable development, interdependence, human rights, diversity. The description of the principles 
and the skills related are discussed in the case study of the proposal of embedding GD in the Hospitality Business Toolkit.

\section{A Conceptual Overview of the Approaches to Embed Global Dimension in Adult Education Curriculum}

As there is no united framework for embedding GD in adult curriculum, the concepts of embedding, infusion, mainstreaming related to GE, GD, ESD and ESDGC are reviewed as interrelated and integrated.

'While the term 'mainstreaming', as in the global indicator of SDG Target 4.7, is commonly used to refer to a process of incorporating or including ESD in different aspects of education systems, we use 'embedding' intentionally to refer to a particular strategy for mainstreaming' (UNESCO MGIEP, 2017, p. 18).

UNESCO MGIEP (2017, p. 18) refer to Wals (2009, p. 49) that mainstreaming ESD into formal education involves different approaches, ranging from 'conventional' ones that conform to existing school systems and structures to 'innovative' ones where there is a radical force to transform existing institutional structures. 'Ideally, mainstreaming ESD should happen within a 'whole-school' approach, with ESD values and principles being reflected in the ethos and mission of the school and being central to the professional development of its teachers (UNESCO MGIEP, 2017, p. 18).

The metaphor of embedding describes the process of integrating a desirable element deeply into a system. Embedding is a strategy that opens up possibilities for transforming the education system from within by paving a way to an interdisciplinary curriculum, issue-based learning and whole-school approaches (UNESCO MGIEP, 2017, p. 18).

The metaphor of infusion, on the other hand, describes the process of a desirable essence permeating and transforming the milieu in which the system operates. Infusion is a strategy for ESD integration that is deeper than embedding and is an ultimate solution (UNESCO MGIEP, 2017, p. 18).

Embedding, therefore, strategically promotes double-purpose learning, where students acquire subject knowledge and skills and, at the same time, learn how to contribute to a sustainable transformation of society - they learn to live together with a deep respect for the environment and dignity for all (UNESCO MGIEP, 2017, p. 19).

One of the most important methodological approaches for understanding globalised themes is to track the same problems and issues at all these levels in order to constantly investigate the relationship between micro and macro context (The GE Guidelines Working Group, 2012, p. 21).

'A holistic approach seeks to understand direct and indirect relationships between forms of power, violence and injustice at all levels, as well as 
the values, practices and necessary conditions needed to overcome them' (GEGWG, 2012, p. 30). Lehner, Wurzenberger (2013) state that 'GE provides holistic learning strategies based on the challenges of globalisation and a global society.

Dumitru (2017, p. 896) demonstrated how ESD principles and competencies can be integrated within its established curricular architecture by means of the method of infusion. The main focus of infusion or the embedding approach referring to Collins et al (1989), Ennis (1989), Perkins and Salmon (1989) is to include new competencies into an existing program and into existing subject matter, making the principles of the new corpus of knowledge explicit to the students. There are two other concurrent approaches, namely: (1) one which consists of adding a new course separately from other subject matters; the new course containing the new knowledge (the stand-alone approach); and (2) immersing the new knowledge into the existing subject matters, without making explicit to the students the principles and newness of the knowledge corpus (Dumitru, 2017, p. 896).

UE4SD (2014, p. 17) illustrates a comparative overview of ESD approaches and principles that are promoted in national strategies. The analysis is based on the three ESD approaches: competence/skillbased, strategic/systemic, whole-of-institution. Estonia, Ireland and Latvia are using only strategic/systemic approach, Lithuania and Hungary are using only competence/skill-based approach, United Kingdom and Greece are using the two approaches - whole-of-institution and competence/ skill-based, but Cyprus use only whole-of-institution. Italy, Portugal and Spain are using whole-of-institution and strategic-systemic approaches. GEGWG (2012, pp. 30-31) determine the three methodological approaches to GE including cooperative-based learning, problem-based learning and dialogue-based learning.

The micro-macro approach mentioned by GEGWG (2012, p. 33) has the three forms. The first form is 'from local to global', the second form is 'from personal to collective', and the third form is 'from emotional to rational'.

Interdisciplinary approach discussed by GEGWG (2012, p. 33) suggests that 'global issues can be developed through any subject of the curricula, formal or non-formal'.

Sustainability and Environmental Education (SEEd, 2016) outlines Whole School or Whole Institution Approach, also called Whole System Approach (Sustainability and Education Academy, SEDA, 2016), which can be of the two categories: whole school engagement on a topic or practice and whole school approaches categorised by an ethos/vision and or a framework (Finalyson, 2016). 
The recommended practices for GE by GEGWG (2012, p. 39) is the project method, the world-links method, international school partnerships, debate competitions, participative arts, community learning, learning to live together by, and sports.

Zhang et al (2016, p. 375) examined and demonstrated a Comparative Perspective of Competency-Oriented Diversity Education by contrasting the two approaches such as mainstream diversity education approach and competency-oriented diversity education approach to culturally and linguistically diverse international students (CLDI students). The competencyoriented diversity education approach ensures both inclusion and academic success, targets both nonmainstream domestic students and CLDI students, sets sustainability as motive: the changing needs and expectations of students with curriculum both informal and formal, and systematic curriculum transformation. The recommended pedagogy is identitysensitive, particularism (different keys for different locks; individualized teaching); proactive learning relationship, and such learning outcomes as diversity awareness; mind-set shifts; host-country language proficiency; cross-cultural knowledge, skills, and abilities Zhang et al (2016, p. 375).

Zhang et al (2016, p. 376) state that OECD business schools may need to reform the traditional standardized course structure and explore the possibility of designing courses specifically to address CLDI students' special educational needs.

By Sweitzer (2019), the subject-centered curriculum design describes what needs to be studied and how it should be studied. Subject-centred curriculum design revolves around a particular subject matter or discipline (Sweitzer, 2019, 'Curriculum Design').

'Learner-centred pedagogy sees students as autonomous learners and emphasizes the active development of knowledge rather than its mere transfer and/or passive learning experiences. Learner-centred approaches require learners to reflect on their own knowledge and learning processes in order to manage and monitor them. Learner-centred approaches change the role of an educator to one of being a facilitator of learning processes' (UNESCO, 2017, p. 55 with reference to Barth, 2015).

In action-oriented learning, action-oriented approach, learners engage in action and reflect on their experiences in terms of the intended learning process and personal development. The experience might come from a project (in-service learning), an internship, the facilitation of a workshop, the implementation of a campaign, etc. Action-learning refers to Kolb's theory of the experiential learning cycle with the following stages including 1) having a concrete experience, 2) observing and reflecting, 3) forming abstract concepts for generalization and 4) applying them in new situations' (UNESCO, 2017, p. 55 referring to Kolb, 1984). 
'Action-learning increases knowledge acquisition, competency development and values clarification by linking abstract concepts to personal experience and the learner's life. The role of the educator is to create a learning environment that prompts learners' experiences and reflexive thought processes' (UNESCO, 2017, p. 55).

'Problem-centered curriculum design, problem-centred approach, is also a form of student-centered design. Problem-centered curricula focus on teaching students how to look at a problem and come up with a solution to the problem. Students are thus exposed to real-life issues, which help them develop skills that are transferable to the real world' (Schweitzer, 2019, 'Curriculum Design').

UNESCO (2009, p. 4), mentions competency-based approach for ESD. 'A global vision of curriculum should include learning outcomes to achieve (exit profiles), pedagogical and instructional strategies linked to teaching and learning, teaching materials for teachers and students, the discipline's contents, evaluation of learning outcomes and achievements, and curriculum management.'

A competency-based approach can be a valid alternative to the notion of a curriculum as a plan of studies, providing an innovative way of conceiving and organizing the curricular structure and objectives, discipline-contents, to develop people who are competent as autonomous, critical and assertive citizens (UNESCO, 2009, p. 4).

An interdisciplinary approach engages students meaningfully in sustainability issues by allowing them to analyze a complex topic in more than one subject (UNESCO MGIEP, 2017, p. 24).

UNESCO (2017, p. 55) mentions transformative learning, transformative learning approach, which can best be defined by its aims and principles, rather than by any concrete teaching or learning strategy (UNESCO, 2017, p. 55).

\section{Entrepreneurial Education Approach}

Based on the Hospitality Business Toolkit competences set up by BTEC and on the Sustainable Development Goal 4 and its target 4.4 'By 2030, substantially increase the number of youth and adults who have relevant skills, including technical and vocational skills, for employment, decent jobs and entrepreneurship' (United Nations, 2015, “The 2030 Agenda for Sustainable Development"), the approaches to teaching and learning entrepreneurship are reviewed.

Lackéus (2015, p. 9) states being entrepreneurial can mean many things to many people, and discusses that a common conception according to Gartner (1990), that entrepreneurship is about entrepreneurial individuals creating innovative organizations that grow and create value, either for 
the purpose of profit or no, entrepreneurship does not have to include the creation of new organizations, it can also occur in existing organizations (Shane and Venkataraman, 2007).

A learning-by-doing approach as fosters habits of learning by default through its deep learning component. It also promotes initiative and responsibility, since it encourages people to take initiative to inter-action of the kind that leads to meaningful outcomes, sometimes even valuable to a wider community (i.e. taking responsibility) (Lackéus, 2015, p. 9).

Lackéus (2015, p. 30) presents the three models from entrepreneurial domain such as Effectuation (Read et al., 2011), Business Model Canvas (Osterwalder and Pigneur, 2010), Customer development /Lean Startup (Blank and Dorf, 2012). In addition, the three other tools from other domains are reviewed such as Appreciative Inquiry (Bushe and Kassam, 2005), Service-learning (Kenworthy-U'Ren et al., 2006) and Design thinking (Dunne and Martin, 2006). All six models are contrasted in such aspects as value creation, interaction with outside world, team work and action.

Lackéus (2015, p. 10) referring to Fayolle and Gailly (2008) stresses that the varying definitions of entrepreneurship and resulting variations in pedagogical approaches have made it difficult to give teachers firm advice on how to approach entrepreneurial education.

Discussion around entrepreneurial education contrasts between a "traditional" and an "entrepreneurial" way of teaching. Positivism is put versus interpretivism, traditional education versus progressive/constructivist education, and traditional education versus entrepreneurial education, scientific method versus entrepreneurial method as contrasted by Lackéus (2015, p. 15). Descriptions of traditional education are 'simplicity, individual, content, detached, theory', but diverged attributes of entrepreneurial education are 'complexity, social, content, process, attached, practice' (Lackéus, 2015, p. 15).

The features explain why entrepreneurial education can trigger much higher levels of motivation, experienced relevancy, engagement and deep learning than can other pedagogical approaches (Lackéus, 2015, p. 15, referring to Lackéus, 2013).

Lackéus (2015, p. 15) specifies major focus of Entrepreneurial Education on 'problems, opportunities, authenticity, artifact creation, iterative experimentation, real world (interaction), value creation to external stakeholders, team-work, work across extended periods of time, newness / innovativeness, risk of failure'. Only problems and authenticity are the focus in compared, 'often stated to be similar' approaches: Entrepreneurial Education, problem-based learning, project-based learning, service learning. Team-work focus appears in problem-based and projectbased learning, artefact creation in project-based learning, work across 
extended period of time in project-based and service learning, additionally service learning involves real world (interaction), value creation to external stakeholders (Lackéus, 2015, p. 15).

'Teachers should give their students assignments to create value (preferably innovative) to external stakeholders based on problems and/ or opportunities the students identify through an iterative process they own themselves and take full responsibility for.' To alleviate the levels of difficulty and uncertainty such an assignment can result in, a team-work approach should be applied giving the students access to increased creative ability and peer learning opportunities. Lackéus (2015, p. 27) outlines the relation between educational assignments involving creation, triggered activities / events including 'interaction with outside world, uncertainty and ambiguity in learning environment, teamwork environment, overcoming competency gaps, presenting in front of others', developed entrepreneurial competencies as 'increased self-efficacy, increased uncertainty and ambiguity tolerance, increased self-insight, formation of entrepreneurial identity, increased marketing skills, and others'

\section{Assessment in entrepreneurial education}

Lackéus (2014, p. 22), contrasted current assessment focus in entrepreneurial education based on Theory of Planned Behavior (TPB), case studies and entrepreneurial outcomes to a future complementing assessment focus proposed to be built on Experience Sampling Method (ESM). TBS is proposed for assessment of thoughts before and immediately after education, case studies as assessment immediately after and years/ decades after education, ESM for thoughts, actions and emotions during education, entrepreneurial outcomes to assess actions years / decades after education (Lackéus, 2014, p. 22).

The CSCT Project Group (2008, p. 189) referring to de Haan (2006) mentions that ESD specifically involves the acquisition of a number of sub competencies subsumed under the term 'Gestaltungskompetenz', which can be translated as 'shaping competence'. 'Gestaltungskompetenz' means "having the skills, competencies and knowledge to enact changes in economic, ecological and social behaviour without such changes always being merely a reaction to pre-existing problems." Thus, the concept of 'Gestaltungskompetenz' is particularly characterised by such key competencies as enable a forward-looking and selfdependent active involvement in the shaping of sustainable development.

For the construction of the study programme the following methods are recommended by CSCT Project Group (2008, pp. 181-183): blended learning, selection of a problem field relevant to society, systematic analysis using the syndrome approach, substantiation with a case study, scenario 
development, project proposals, synthesis of the development paths. All these six stages are delineated in the systematic approach of the study programme (The CSCT Project Group, 2008, p. 183).

UNESCO (2017, p. 7) states what ESD requires is 'a shift from teaching to learning. It asks for an action-oriented, transformative pedagogy, which supports self-directed learning, participation and collaboration, problem-orientation, inter- and transdisciplinarity and the linking of formal and informal learning. Only such pedagogical approaches make possible the development of the key competencies needed for promoting sustainable development.'

GE, GD, ESD, ESDGC can be embedded in course description, context, topics and subtopics, teaching and learning materials, delivery methods, activities; the role of the teacher, learning environment, assessment, feedback and self-reflection.

The concepts of approaches to embed GD and related meanings as GE, ESD, ESDGC have been demonstrated. The list of approaches varies on the basis of the purpose of embedding considering the discussed benefits and drawbacks.

\section{Learning Challenges}

The four learning challenges by Lehner, Wurzenberger (2013, p. 361), referring to Lang-Wojtasik (2013) and approaches from Selby and Rathenow (2006), are spatial, objective/issues, temporal, social.

Fook, Sidhu (2015, p. 608-610) have delineated the following learning challenges by students in higher education: cognitive challenge, becoming an active learner, coping with reading materials, language problem, instructional problem, time management, assignment burdens, culture difference.

\section{Research Methods}

The grounded theory, an exploratory method, was used for identification and conceptualization of the patterns to structure findings by the process of comparison of different approaches and practices in including qualitative and quantitative analyses. A case study was designed to demonstrate a practical application of optional embedding GD in the course design.

Research Question is in what ways GD can be embedded in Adult Curriculum to achieve Sustainable Development Goals' targets including SD4 Quality Education and overall enhancing education.

\section{The Case Study 'Embedding Global Dimension in the Hospitality Business Toolkit'}

The case provides practical examples on the basis of grounded theory of embedding Global Dimension, ESD, ESDGC in the Unit 'The Hospitality 
Business Toolkit" by HOTEL SCHOOL Hotel Management College, Riga, Latvia. The Unit 'The Hospitality Business Toolkit' is one of the units of the Hospitality Management Programme 2018, BTEC, Higher National Diploma, UK, Level 5, credit value 15, designed by Pearson, the Business and Technology Education Council (BTEC). The course is core, mandatory group, A. (Pearson BTEC, 2017, p. 102), teaching and learning language is English.

According to Pearson BTEC (2017, p. 11), 'students need both relevant qualifications and employability skills to enhance their career prospects and contribute to their personal development. Where employability skills are referred to in this specification, this generally refers to skills in five main categories: cognitive and problem-solving skills, intra-personal skills, interpersonal skills, commercial skills, business skills in addition with academic study skills (Pearson BTEC, 2017, p. 12).

The unit 'the Hospitality Business Toolkit' includes the learning outcomes related to the Finance in the Hospitality industry, Law for Licensed Premises, and Human Resource Management and coordination of the departments related to Operational Management (Pearson BTEC, 2017, pp. 102-108).

By contrasting the eight principles of Global Dimension and the learning outcomes, the included topics in the unit by BTEC Pearson (2017, p. 102-108), the embedding of GD principles has been evidenced in the course.

The GD principle 'global citizenship', described as gaining the knowledge, skills and understanding of concepts and institutions necessary to become informed, active, responsible citizens (McGough, Hunt, 2012, p. 5-6), is embedded in learning outcome LO3 'illustrate the potential impact of legal and ethical considerations on a hospitality business' with assessment criteria 'critically reflect on the potential impacts of regulations, legislation and ethical principles upon decision-making in a hospitality organisation, providing specific examples (BTEC Pearson, 2017, pp. 102-108).

The GD principles 'conflict resolution', 'social justice', 'human rights', 'diversity' (McGough, Hunt, 2012, p. 5-6), are embedded in LO3 and LO2 'assess how to manage the Human Resources life cycle within the context of HR strategy' with assessment criteria 'make valid judgements and recommendations on how HR processes and documents can be improved for effective talent planning throughout the HR life cycle' for Distinction level.

The GD principle 'values and perceptions', explained as 'developing a critical evaluation of representations of global issues and an appreciation of the effect these have on people's attitudes and values' (McGough, Hunt, 2012, p. 5-6) can be found in LO1, LO2, LO3 and LO4, where LO1 is 'investigate how to manage finance and record transactions to 
minimise costs responsibly within the hospitality sector', but LO4 is 'explain the importance of coordinating and integrating various functions of departments within the hospitality sector' with assessment criteria 'critically analyse different methods of communication, coordination and monitoring within a specific department of a hospitality organisation and make justified recommendations' (Pearson BTEC, 2017, pp. 102-108).

The GD principle 'interdependence', understanding how people, places, economies and environments are all inextricably interrelated, and that choices and events have repercussions on a global scale and the principle 'sustainable development', (McGough, Hunt, 2012, p. 5-6) are traced to all four learning outcomes.

The GD skills, delineated by McGough, Hunt (2012, p. 8), are evinced as embedded in the Hospitality Business Toolkit learning content and outcomes including 'understanding that people have different values, attitudes and perceptions, understanding the importance and value of human rights, developing multiple perspectives and new ways of seeing events, issues, problems and opinions, questioning and challenging assumptions and perceptions, understanding the power of the media in influencing perceptions, choices and lifestyles, understanding that the values people hold shape their actions, using different issues, events and problems to explore children and young people's own values and perceptions as well as those of others' (McGough, Hunt, 2012, p. 5-6).

As alternative pattern, GD Principle 'Sustainable Development' Skills traced to the Hospitality Business Toolkit Selective Content of the Unit Topics including 'recognising that some of the earth's resources are finite and therefore must be used responsibly by each of us' (McGough, Hunt, 2012, p. 5-6): control of resource allocation: stock taking, inventory costings, systems of waste management, flagging cost control issues and progress in terms of targets and expectations (Pearson BTEC, 2017, pp. 102-108).

Another example of the embedded skills to obtain in the course 'considering probable and preferable futures and how to achieve the latter' (McGough, Hunt, 2012, p. 5-6) related to the topics such as use of budgets for planning and control: income streams, fixed costs and variable costs, methods of forecasting to set realistic profit margin targets, pricing strategies and setting realistic targets; performance management, training and development, succession planning and maintaining employee motivation to retain staff (Pearson BTEC, 2017, pp. 102-108).

Adjoining the options of embedding GD, SD, ESDGC are explained with respect to the 'following recommended actions to ensure effective education and training with regard to green economies and green societies as integrate sustainable development into education and training at all levels, 
and cultivate key competencies required to facilitate the transition to sustainability, such as entrepreneurship and risk management skills in order to 1) enhance education for entrepreneurship skills to promote the launch of new enterprises and self-employment directly and indirectly related to the green economy, 2) provide entrepreneurship training and business coaching for young people and adults to start up green businesses in conjunction with microfinance projects in developing countries (UNESCO, 2012, pp. 6-7).

The assignment set up for the unit include the four separate task submissions with different deadlines according to the delivered sessions, materials and time necessary to perfume the tasks.

The first assignment part is development of the Risk Management Plan, the report and presentation, group work up to 5 persons. The learners (described in Investigation Results) carry out a detailed risk assessment for one type of licensed premises. In addition, the students reflect on such aspects as International Environmental Standards and its benefits, certification, environmental management programs, ISO, EMAS, environmental quality signs, eco labels, sustainable business ethics, Corporate Social Responsibility (CSR) (Zvereva, 2019, 'Assignment').

The second assignment part is Financial Business Plan of the value added business idea to a new hospitality business or an existing hospitality business including the three financial scenarios of the business idea budget, trial balance, financial analysis with analysis of energy consumption and proposal for optimization (Zvereva, 2019, 'Assignment').

The third part of the assignment is participation in the X-Culture Global Collaboration Course (North Carolina, the U.S.) involving theoretical training and two months of practical experience as a member of a Global Virtual Team. The teams develop a high-quality business plan for a multinational company working alongside over 5,000 students from 110-150 universities in over 40 countries on 6 continents. The students get random allocation on teams after passing the pre-readiness test to get acquainted with the instructions, communicate to the team members from different countries to develop a business proposal according to set framework and milestones (X-Culture Project, 2019, www.X-culture.org).

The forth part of the assignment is the individual task, preparing a Human Resource Management Plan or HR Training Programme for a specific hospitality job with analysis and recommendations of corporate governance structure, HR system, ethics in the hospitality business company, with sustainability focus (Zvereva, 2019, 'Assignment').

The optional embedding is via adaptation of the course title focusing on the sustainability with change to the Sustainable Hospitality Business Toolkit, the definition of the sustainable hospitality will be centred for the content. The length of the course also can be extended at programme 
technical possibilities and necessity in case of adding the additional content depending on the standards.

The learning outcome is supplemented by the word 'sustainable' attached to the HR strategy, that changes the meaning and definitions to be delivered - regard managing the Human Resources (HR) life cycle within the context of sustainable HR strategy, where the students learn not just the HR strategy, but specifically sustainable HR strategy in addition or instead by choice of the option.

In order to embed the GD, ESD, ESDGC content in the course, the listed examples of the topics can be added: sustainable management, sustainability performance indicators (SPIs) or sustainable development indicators, Sustainable Finance, activities of sustainable finance, benefits of organizing for sustainability to the bottom line, Sustainability Accounting Standards, Sustainability Accounting Standards (Zvereva, 2019, 'Assignment').

The topic Energy can be embedded in the unit as the part of the theme Financial Management and Recording Transactions to Minimize Costs Responsibly within the Hospitality Sector via subtopics sustainable budgeting and control of resource allocation with example how to use GRI Indicators to measure company performance in energy consumption, resource control and saving within the Environmental Aspect by Energy and to build company performance analysis and budgeting on the GRI Indicator (GSSB, 2016, "Global Reporting Indicators").

It is proposed to apply ESD principles in development of the design of the materials: vertical layout, neutral colours, and most friendly fonts to reading thus embedding health topic into design. Learning environment choice related to Sustainable Hospitality Business can be a site, where SD principles should be implemented as soon as possible or a site, where SD principles have been already implemented - open nature or alternative energy site related to hospitality business.

\section{Investigation Results}

A synthesis of approaches has been applied by embedding the GD in the Hospitality Business Toolkit including subject-oriented approach, action-by-learning approach, competence-based approach, competencybased approach, holistic approach, Entrepreneurial Education approach. The GD was embedded at all levels of the unit delivery.

The unit was delivered from February 2019 by May 2019 to 30 students, $96.6 \%$ students have started the course with the average attendance $59 \%$ and average rate of regular $83.3 \%$ of attendees was $69 \%$.

In the frame of the third part of the assignment, 29 students have applied for participation in X-Culture project from March 05, 2019 by 
April 28, 2019. In total, 23 students of 29 (79.31\%), average age 19 years old, from 9 countries were not excluded by the team and by the results during the project. Collectively, there were 698 teams with average 5-7 students on team. The average grade in the project track is $5.24(74.86 \%)$ of scale 7 (X-Culture, 2019), the average grade of 22 Hotel School students of 23 in the list graded by 5-7 professors per report is $5.3(75.71 \%)$ of 7 . One of the students from Sri Lanka got in the list of the winning 40 best teams of 698 teams.

Analysing the results of the first task of the group assignment, Risk Management Plan, 23.4\% of students have received 9 and Distinction, $40 \%$ of students -8 and Merit, $16.6 \%$ of students - Pass from 5 to $7,20 \%$ of students have no grades.

Total results of the individual exam in addition to BTEC assessment criteria are the following: 24 (80\%) students of 30 have taken the exam with $100 \%$ positive results.

The final positive grades in the Unit were received by 26 (86.67\%) of the 30 students with possibility to improve BTEC criteria in assignments at timely first submission. The final grades for criteria $\mathrm{P}, \mathrm{M}$ and D involve meeting all criteria included in the programme by Pearson BTEC (2018, p. 102-108). However, the tutor auxiliary has applied the formative assessment by the two mid-term tests and the final exam for the numeric grading in addition to $\mathrm{P}, \mathrm{M}, \mathrm{D}$ scale.

\section{Analysis of Achieved Learning Outcomes and Grading}

Based on the conducted analysis of the results, the findings suggest that in general the results of the group work are higher than individual, therefore, it is important to include both group and individual tasks to assess the achievement of learning outcomes. On the other hand, the group work opens additional experience sharing and collaboration experience traced to employability skills and sustainable development.

During the unit completion, the students have faced such challenges as coping with reading materials, language problem, time management, assignment burdens, culture difference based on the submissions, however, it is recommended to consider a future study of the learning challenges identified by the learners.

\section{Discussion}

The utmost importance is in the synthesis and integrity of the criteria and approaches to be applied to embed GD, ESD, ESDGC in the competence based units with variety of the methods of the assessment to enable 
a holistic approach as it has been piloted by the case of the Hospitality Business Toolkit.

Another point to discuss is that in previous programme the Finance Unit was included in the third term when the students are already experienced in BTEC criteria system and have basic knowledge in other units, but the updated programme sets the Hospitality Business Unit as the first term unit when students face with law, financial management and accounting built in the Business Toolkit Unit.

\section{Conclusions}

The most obvious finding of this study is that a synthesis of approaches to embed GD, ESD, ESDGC in the curriculum is of utmost importance. The balance should be kept between values, employability skills and, in particular, financial literacy. The weight of the focus on values and employability skills should not denominate the significance of the competences and particular aspects as financial literacy. The unity between the content, form and context in which the learning process takes place is significant for designing teaching-learning-evaluating strategies as from theory review.

It is very important for the tutors and programme leads to orientate among the variety of approaches to use them for efficiency and enhancing overall quality including grading, values, actions by the learners.

The response to the research question has been provided by studying and demonstrating the ways GD can be embedded in Adult Curriculum to achieve Sustainable Development Goals' targets including SD4 Quality Education and overall enhancing education.

The Aim of the Research is achieved by performed objectives, a conceptual overview of the approaches to embed GD in Adult Education Curriculum has been presented.

The research raised the questions to study in future exploration. The theory review demonstrates the diversity of theoretical and practical application of the approaches to embedding ESDGC and GD as well as absence of exact framework solution and data.

\section{Contribution}

An extensive literature review as a conclusion of the EU Erasmus KA2 Project Intellectual Outputs on embedding ESDGC and GD conducted collaboratively and individually has been presented in order to demonstrate the existing spectrum of approaches noted for embedding GD, ESD, ESDGC not to denominate any of the mentioned approach as each of them 
individually might be of utmost importance for the designs of effective curriculums, courses, assignments.

\section{Limitations}

The case is based on a single case analysis with the limited number of students, which is, however, a vivid international example of the approaches and techniques to embed GD, ESD, ESDGC in the curriculum and course design. The unit was delivered as first time delivery with embedded GD, ESD, ESDGC without an opportunity to compare the historic results of the same unit delivery excluding embedded GD, ESD, ESDGC as well as comparing several deliveries of the same unit set.

\section{Recommendations for Further Research}

As further research, the results of the same unit delivery over several terms are suggested to be investigated to work out the result statistics and study the influencing factors, the most effective and least effective approach taking into consideration multicultural students and institution external environment to focus on the approach combination taking in consideration the prior learning challenges in different regions.

\section{Acknowledgements}

Expressing gratitude to Pearson BTEC for the shared experiences, $\mathrm{X}$-Culture research partners and the partners of EU Erasmus Plus Project for cooperation and opportunity for research extension.

\section{References}

Barth, M. (2015). Implementing sustainability in higher education: learning in an age of transformation. London, Routledge.

Bourn, D. (2012). Global learning and subject knowledge. Development Education Research Centre. Institute of Education London International Development Centre, p. 8. Retrieved from https://www.ucl.ac.uk/ioe/sites/ioe/files/GlobalLearningAnd SubjectKnowledge.pdf.

Collins, A., Brown, J. S. and Newman, S. (1989), "The new apprenticeship: teaching students the craft of reading, writing and mathematics", in Resnick, L. B. (Eds.), Knowing, Learning and Instruction, Erlbaum, Hillsdale, NJ, pp. 453-494.

Development Education Association. (2000). Developing a global dimension in the school curriculum, p. 3. Retrieved from https://dera.ioe.ac.uk/6152/7/globald_Redacted.pdf.

Dumitru, D. E. (2017). "Reorienting higher education pedagogical and professional development curricula toward sustainability - a Romanian perspective", International 
Journal of Sustainability in Higher Education, Vol. 18, Issue 6, p. 896. Retrieved from https://doi.org/10.1108/ IJSHE-03-2016-0046.

Europe-wide Global Education Congress. (2002). The Maastricht Global Education Declaration, p. 2. Retrieved from https://rm.coe.int/168070e540.

Finalyson, A. (2016). Whole School/Institution Approaches to Education for Sustainable Development (ESD). (SEEd). Retrieved from https://se-ed.co.uk/edu/wholeschoolinstitution-approaches-education-sustainable-development-esd-backgrounder/.

Fook, C. Y., Sidhu, G. K. (2015). Investigating Learning Challenges faced by Students in Higher Education. Procedia. Social and Behavioural Sciences, pp. 608-610. Retrieved from https://www.sciencedirect.com/science/article/pii/S1877042815022612.

Gartner, W. B. (1990). What are we talking about when we talk about entrepreneurship? Journal of Business Venturing, 5, pp. 15-28. Retrieved from https://econpapers.repec.org/scripts/redir.pf?u $=$ http\%3A\%2F\%2Fwww.sciencedirect. com\%2Fscience\%2Farticle\%2Fpii\%2F0883-9026\%2890\%2990023-M; h = repec:eee:jbve nt:v:5:y:1990:i:1:p:15-28.

GSSB. (2016). GRI 302: Energy. GRI Standards. Retrieved from https://www. globalreporting.org/standards/media/1009/gri-302-energy-2016.pdf.

Hopkins, C. et al. (2016). Contributions of Education for Sustainable Development (ESD) to Quality Education: A Synthesis of Research. Journal of Education for Sustainable Development 10:2. p. 228. Retrieved from https://journals.sagepub.com/ doi/full/10.1177/0973408216661442.

Kenworthy-U'ren, A., Taylor, M. \& Petri, A. (2006). Components of successful servicelearning programs: notes from Barbara Holland, Director of the US NationalService-Learning Clearinghouse. International Journal of Case Method Research and Application, 18, pp. 120-129. Retrieved from https://research.bond.edu.au/en/publications/componentsof-successful-service-learning-programs-notes-from-bar.

Kolb, D. A. (1984). Experiential Learning: Experience as the Source of Learning and Development. Englewood Cliffs, N. J., Prentice-Hall.

Lackéus, M. (2015). Entrepreneurship in Education. Local Economic and Employment Development) Division of the OECD, pp. 9-27. Retrieved from https://www. schooleducationgateway.eu/downloads/entrepreneurship/40.1\%200ECD\%20(2014)_ BGP_Entrepreneurship\%20in\%20Education.pdf.

Lehner, D., Wurzenberger, J. (2013). "Global Education - an educational perspective to cope with globalisation?", Campus-Wide Information Systems, Vol. 30, Issue 5, p. 361. Retrieved from https://doi.org/10.1108/.

Mannion, G., Biesta, G., Priestley, M. \& Ross, H. (2011). The global dimension in education and education for global citizenship: genealogy and critique. Globalisation, Societies and Education, 9:3-4, 443-456, DOI: 10.1080/14767724.2011.605327. Routledge Francis \& Son, pp. 448-452. Retrieved from https://doi.org/10.1080/1476 7724.2011.605327.

McGough, H., Hunt, F. (2012). The Global Dimension: A Practical Handbook for Teacher Educator Development Education. Institute of Education. University of London Research Centre, pp. 5-8. Retrieved from https://www.ucl.ac.uk/ioe/sites/ioe/files/ franhunthannahpracticalhandbook.pdf.

Pearson BTEC. (2017).The Hospitality Business Toolkit. Hospitality Management Programme 2018. Issue 1, pp. 11-12, 102-108. 
Perkins, D. N., Salmon, G. (1989), “Are cognitive skills context bound?", Educational Researcher, Vol. 18, pp. 16-25.

Qualifications and Curriculum Authority. (2008). The global dimension in action. A curriculum planning guide for schools, p. 2. Retrieved from https://www. globalfootprints.org/files/zones/hec/QCA_global_dimension_in_action.pdf.

Schweitzer, K. (2019). Curriculum Design: Definition, Purpose and Types. Retrieved from https://www.thoughtco.com/curriculum-design-definition-4154176.

SEDA. (2016). Domain Framework for Whole System Approach to ESD. Sustainability and Education Academy. Retrieved from https://www.edu.gov.mb.ca/k12/esd/pdfs/ seda_domain_framework.pdf.

Selby, D. and Rathenow, H. (2006), Globales Lernen. Praxishandbuch für die Sekundarstufe I und II, Cornelsen, Berlin, pp. 15-18.

Shane, S. \& Venkataraman, S. (2007). The Promise of Entrepreneurship as a Field of Research*. Entrepreneurship. Springer. Retrieved from https://link.springer.com/ chapter/10.1007/978-3-540-48543-8_8.

Sustainability and Environmental Education (SEEd). (2016). Whole School/Institution Approaches to Education for Sustainable Development (ESD). Retrieved from https://seed.co.uk/edu/whole-schoolinstitution-approaches-education-sustainable-developmentesd-backgrounder/.

The CSCT Project. (2008). Competencies for ESD (Education for Sustainable Development) teachers. A framework to integrate ESD in the curriculum of teacher training institutes, pp. 183, 189-192. Retrieved from https://www.unece.org/fileadmin/ DAM/env/esd/inf.meeting.docs/EGC/CSCT_Handbook_11_01_08.pdf.

The Department for International Development (DFID). (2005). Developing the global dimension in the school curriculum, pp. 7, 20. Retrieved from http://www.education. gov.uk/publications/eOrderingDownload/1409-2005DOC-EN-02.doc.

The Global Education Guidelines Working Group. (GEGWG). (2012). Global Education Guidelines Concepts and Methodologies on Global Education for Educators and Policy Makers. The North-South Centre of the Council of Europe, pp. 17, 21-24, 30-39. Retrieved from https://rm.coe.int/168070eb85.

UE4SD (2014), "Mapping opportunities for professional development of university educators in Education for Sustainable Development: A state of the art report across 33 UE4SD partner countries", in Mader, M., Tilbury, D., Dlouhá, J., Benayas, J., Michelsen, G., Mader, C., Burandt, S., Ryan, A., Barton, A., Dlouhý, J., and Alba, D. (Eds.), University of Gloucestershire, Cheltenham, pp. 17, 57. Retrieved from www. ue4sd.eu/images/RegionalMapping/UE4SD_State-of-the-art-report.pdf.

UNESCO. (2017). Education for Sustainable Development Goals. Learning Objectives, pp. 17-18, 53-57. Retrieved from https://www.iau-hesd.net/sites/default/files/ documents/247444e.pdf.

UNESCO. (2009) Training Guideline on incorporating Education for Sustainable Development (ESD) into the curriculum, pp. 4-5. Retrieved from http://www.ibe. unesco.org/sites/default/files/ESD_training_guidelines_-3.pdf.

United Nations Educational, Scientific and Cultural Organization Mahatma Gandhi Institute of Education for Peace and Sustainable Development. (UNESCO MGIEP). (2017). Textbooks for sustainable development: a guide to embedding. India, pp. 18-19, 24, 49. Retrieved from https://unesdoc.unesco.org/ark:/48223/pf0000259932. 
United Nations. (2015). 17 Sustainable Development Goals. The 2030 Agenda for Sustainable Development and its 17 Sustainable Development Goals. Retrieved from https://www.un.org/sustainabledevelopment/development-agenda/.

X-Culture Global Collaboration Project for Business Students. (2019). Retrieved from www.x-culture.org.

Zhang, M. M. (2016). Managing Student Diversity in Business Education: Incorporating Campus Diversity into the Curriculum to Foster Inclusion and Academic Success of International Students. Learning \& Education, 2016, Vol. 15, No. 2, pp. 366-380. Academy of Management. Retrieved from http://dx.doi.org/10.5465/amle.2014.0023.

Zvereva, O. (2019). The Hospitality Business Toolkit Assignment 2019. Hotel School Hotel Management College. 